\title{
Paraneoplastic Upbeat Nystagmus in Renal Cell Carcinoma
}

Marcello Cherchi ${ }^{*}$

Departments of Neurology, Northwestern University Feinberg School of Medicine, USA

*Corresponding author: Marcello Cherchi, Assistant professor, Northwestern University, Abbott Hall, 11th Floor Chicago, IL 60611-3078, USA; E-mail: mcherchi2@md.northwestern.edu

Received date: February 10, 2015; Accepted date: April 23, 2015; Published date: April 27, 2015

Copyright: (C2015 Cherchi M. This is an open-access article distributed under the terms of the Creative Commons Attribution License, which permits unrestricted use, distribution, and reproduction in any medium, provided the original author and source are credited.

\section{Case}

A 72 year-old man with a longstanding past medical history of hypertension and restless legs syndrome presented with a chief complaint of unsteadiness and oscillopsia that he reported as starting abruptly three months previously, with rapid deterioration. As the unsteadiness progressed, it also became associated with nausea, to which he attributed an unintentional 10-pound weight loss over 1 month. He denied any other symptoms, including other stigmata of malignancy (new cough, bleeding in the urine or stool). He did not drink alcohol, but smoked 1 pack of cigarettes per day. His only medications were lisinopril and gabapentin. He reported no family medical history.

Some of his workup had been completed before he presented to our clinic. Audiometry showed presbycusis. MRI of the brain and internal auditory canals without and with contrast was normal; specifically, there were no abnormalities in the cerebellum. Lumbar puncture reported cerebrospinal fluid protein elevated at 70 (normal $15-45$ ), IgG elevated at 4.38 (normal $0.00-3.40$ ), albumin elevated at 47.50 (normal 0.00 - 34.99). Lyme disease antibody screen was negative and myelin basic protein was $<2.0$ (normal $0-4.0$ ). Serum antibodies to $\mathrm{Hu}, \mathrm{Yo}$ and Ri were negative.

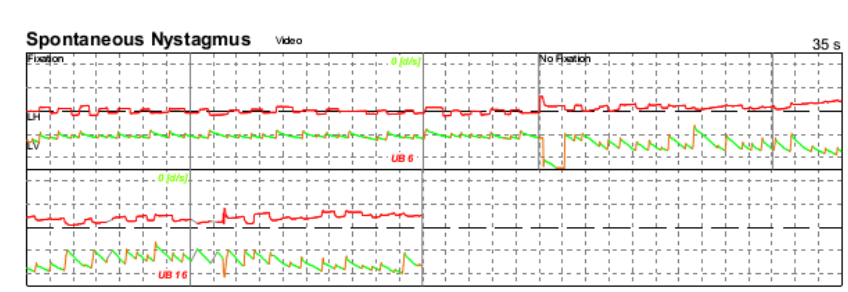

Figure 1: Videonystagmography tracing showing spontaneous upbeat nystagmus. The vertical grid lines represent one-second intervals. The tracing labeled "LH" represents the horizontal position of the left eye; the tracing labeled " $L V$ " represents the vertical position of the left eye. The first 22 seconds of the tracing, in which the patient was permitted to fixate on a target, shows 6 $\mathrm{deg} / \mathrm{sec}$ upbeat nystagmus; when vision (and therefore the ability to fixate) is denied, the upbeat nystagmus increases in velocity to 16 $\mathrm{deg} / \mathrm{sec}$.

He came to clinic in a wheelchair because he was unable to ambulate or transfer independently. On physical examination he had spontaneous upbeat nystagmus on primary position of gaze (16 $\mathrm{deg} / \mathrm{sec}$ in the dark, diminished to $6 \mathrm{deg} / \mathrm{sec}$ with fixation; see Figure 1 and Video), which also intruded into smooth pursuit. The upbeat nystagmus did not change at the extremes of lateral gaze, nor did it depend on position with respect to gravity. The remainder of his examination, including appendicular cerebellar function, was normal.

Having examined him in clinic, we referred him immediately for CT of the chest, abdomen and pelvis without and with oral and intravenous contrast, which revealed a $2 \mathrm{~cm}$ solid focal partially exophytic mass in the left kidney.

Subsequent workup included MRI of the abdomen that demonstrated the same renal mass. An F18 FDG PET scan showed increased uptake in this renal mass, as well as mildly increased uptake in a precarinal lymph node. Transbronchial needle biopsy of a right paratracheal lymph node was negative for carcinoma and lymphoma. A separate FDGPET/CT study showed increased uptake in a right abdominal precaval mesenteric lymph node; needle biopsy found this to be inflammatory, without evidence of malignancy. A second lumbar puncture had an opening pressure of $120 \mathrm{~mm} \mathrm{H} 2 \mathrm{O}$. Cerebrospinal fluid had a protein of 112 and a lymphocytic pleocytosis of 16 and no red cells; IgG index and synthesis were normal; oligoclonal bands were negative; cytology was negative. Cerebrospinal fluid infectious studies were negative, including VDRL, Blastomyces, Coccidioides, Cryptococcus, yeast, fungi, adenovirus, LaCrosse encephalitis virus, cytomegalovirus, Epstein-Barr virus, Herpes simplex virus 1/2, HHV6, JC virus, St. Louis enephalitus virus, Varicella zoster virus, Eastern and Western equine encephalitis virus. Serum studies showed a positive SSA antibody. Serum copper was within the normal range. Other negative or normal studies included vitamin B12, methylmalonic acid, HIV $1 / 2$ antibodies, IgA tissue transglutaminase assay and quantiferon. A paraneoplastic panel showed negative or normal results for antibodies to AChR binding and ganglionic neuronal units, ANNA1, ANNA2, ANNA3, AGNA1, PCA1, PCA2, PCATr, amphiphysin, CRMP5 IgG (confirmed on Western blot), striated muscle, Ntype calcium channel, P/Qtype calcium channel, GAD65, neuronal $\mathrm{K}$ channel. Electromyography with nerve conduction velocities reported myoclonus of cortical origin with a prominent component of orthostatic myoclonus.

He underwent partial left nephrectomy for a localized, grade $1 / 4$ papillary renal cell carcinoma with negative margins. After surgery the patient reported modest improvement in his ambulation and oscillopsia, though he remained significantly impaired. A trial of prednisone brought no additional benefit.

\section{Discussion}

Spontaneous upbeat nystagmus on primary position of gaze has been reported frequently in association with focal pontine lesions [1-3], and also occurs in the presence of nicotine [4,5] and a variety of centrally acting medications. Ko and colleagues [6] state that can also occur in paraneoplastic cerebellar degeneration, though reports of this are rare; it has been described in the presence of anti-Hu antibodies 
associated with pancreatic carcinoma [7] and anti-Ma2 antibodies [8] in which the primary neoplasm was not identified.

The mechanism by which a paraneoplastic syndrome causes upbeat nystagmus is uncertain. Wray and colleagues [7] suggest imbalance of central otolithic projections from autoimmune attack on the nodulus and ventral uvula, based on the fact that their patient's nystagmus was "strongly dependent on head position," meaning that the upbeat nystagmus was absent in the supine position, and supine positional testing on either side provoked apogeotropic nystagmus. In our case this positional dependence was absent, so we are inclined towards Pierrot-Deseilligny and colleagues' hypothesis [9] that upbeat nystagmus results from dysfunction of the crossing ventral tegmental tract [10]. Paraneoplastic diseases involving the central nervous system are thought to affect surface neuronal antigens[11] but why the crossing ventral tegmental tract should exhibit selective vulnerability to paraneoplastic antibodies in this case is unknown.

\section{Conclusion}

The most common oculomotor abnormality associated with paraneoplastic syndromes in adults that we observe in our clinical practice is spontaneous downbeat nystagmus on primary position of gaze. Though rare, the present case illustrates that spontaneous upbeat nystagmus on primary position of gaze should raise suspicion of cancer, even when the history is not otherwise particularly suggestive of malignancy.

\section{References}

1. Pierrot-Deseilligny C, Milea D (2005) Vertical nystagmus: clinical facts and hypotheses. Brain 128: 1237-1246.

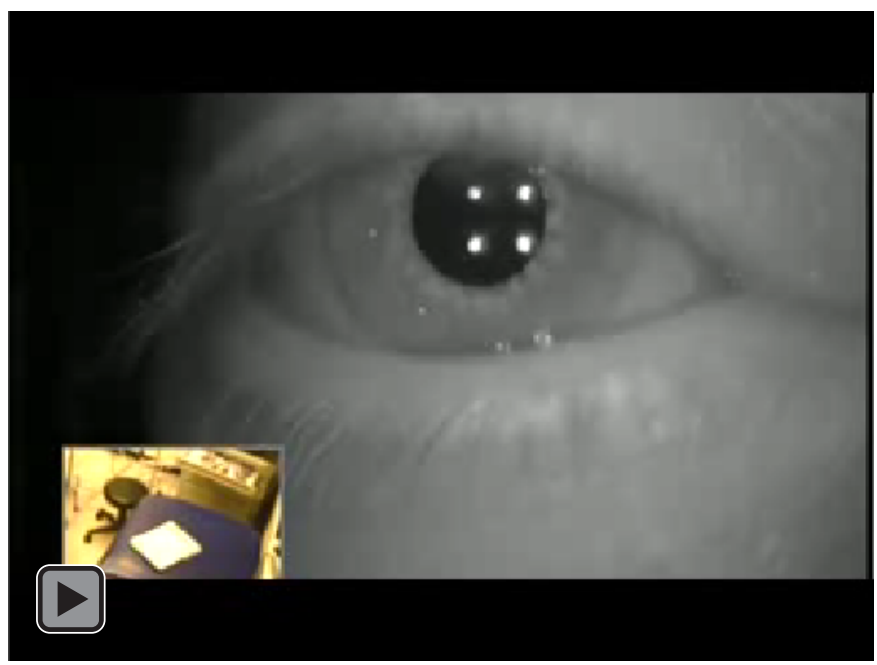

2. Hirose G, Kawada J, Tsukada K, Yoshioka A, Sharpe JA (1991) Upbeat nystagmus: clinicopathological and pathophysiological considerations. J Neurol Sci 105: 159-167.

3. Lee SC, Lee SH, Lee KY, Lee YJ, Koh SH (2009). Transient upbeat nystagmus due to unilateral focal pontine infarction. Journal of clinical neuroscience: official journal of the Neurosurgical Society of Australasia 16: 563-565.

4. Sibony PA, Evinger C, Manning KA (1987) Tobacco-induced primaryposition upbeat nystagmus. Ann Neurol 21: 53-58.

5. Kim JI, Somers JT, Stahl JS, Bhidayasiri R, Leigh RJ. Vertical nystagmus in normal subjects: effects of head position, nicotine and scopolamine. Journal of vestibular research : equilibrium \& orientation 10: 291-300.

6. Ko MW, Dalmau J, Galetta SL (2008) Neuro-ophthalmologic manifestations of paraneoplastic syndromes. J Neuroophthalmol 28: 58-68.

7. Wray SH, Martinez-Hernandez E, Dalmau J, Maheshwari A, Chen A, et al. (2011) Paraneoplastic upbeat nystagmus. Neurology 77: 691-693.

8. Garcia-Reitboeck P, Thompson G, Johns P, Al Wahab Y, Omer S, et al. (2014) Upbeat nystagmus in anti-Ma2 encephalitis. Pract Neurol 14: 36-38.

9. Pierrot-Deseilligny C, Milea D, Sirmai J, Papeix C, Rivaud-Péchoux S (2005) Upbeat nystagmus due to a small pontine lesion: evidence for the existence of a crossing ventral tegmental tract. Eur Neurol 54: 186-190.

10. Ranalli PJ, Sharpe JA (1988) Upbeat nystagmus and the ventral tegmental pathway of the upward vestibulo-ocular reflex. Neurology 38: 1329-1330.

11. Graus F, Saiz A, Dalmau J (2010) Antibodies and neuronal autoimmune disorders of the CNS. J Neurol 257: 509-517. 